\title{
Research on the Network Structure and Evolution of Spatial Distribution of Universities' Cross-Regional Technology Transfer
}

\author{
Yi Tang, Wei Song \\ The School of Public Affairs, University of Science and Technology of China, Hefei, China \\ Email: tang2006122@126.com
}

How to cite this paper: Tang, Y. and Song, W. (2017) Research on the Network Structure and Evolution of Spatial Distribution of Universities' Cross-Regional Technology Transfer. Journal of Service Science and Management, 10, 112-124.

https://doi.org/10.4236/jssm.2017.102010

Received: March 4, 2017

Accepted: April 10, 2017

Published: April 13, 2017

Copyright ( 92017 by authors and Scientific Research Publishing Inc. This work is licensed under the Creative Commons Attribution International License (CC BY 4.0).

http://creativecommons.org/licenses/by/4.0/

\begin{abstract}
Universities are important components of national innovation systems. Their cross-regional technology transfer is of great importance for narrowing regional technology gaps and realizing collaborative innovation. Based on 20072016 patent assignment data of Chinese university, this paper investigates the network structure and evolution law of spatial distribution of universities' cross-regional technology transfer through the social network analysis and GIS spatial analysis. Results show that: (1) Areas with abundant education resources have advantages at technology export, while economically developed areas have become the main target for technology import. In China, the development of technology export and import is generally imbalanced within a province; (2) In the evolution process of technology transfer structure, the dyadic relationship usually turn from a "strong-weak" relationship to a "strong-strong" one, and there exists a positive correlation between the equalization level of the nodes in the structure and the transfer level of universities' technology; (3) The evolution of the spatial distribution of universities' technology transfer demonstrates a trend of diffusion from core areas located on the south-east coast to inland areas. Provinces in the core areas can significantly promote the technology transfer level of surrounding provinces, and an obvious geographic feature is shown in the universities' technology transfer between different areas.
\end{abstract}

\section{Keywords}

University, Cross-Regional Technology Transfer, Network Structure, Spatial Distribution

\section{Introduction}

In the past, most of the universities in China focused on fundamental research 
and education, technical achievements belong to national government. Few technologies were transferred to industries and achieved commercialization. However, with the development of the economic and the transformation of the economic growth mode, universities' cross-regional technology transfer is regarded as a useful way to narrow regional gap and assist in economic development. As an important source of technology innovation, universities are a vital part in the innovation system of countries and regions. Ministry of Education and Technology has indicated in the document of "Opinions on improving universities' technology outcome transformation" that technology transformation is a critical section of universities' technological activities, and to promote it would considerably achieve innovation-driven development and improve universities' ability of serving the society.

Since technology transformation involves knowledge flow, the process can not only achieve commercialization of universities' technology but also positively influence the local industries and economy. Besides, there exists a significant difference in technological resources, innovation capability and economic development between different regions due to factors such as resource distribution and surrounding environment and technology transformation can effectively bridge this gap and realize mutual development. With the development of technology transfer, the research on that area is becoming more and more important. Through status analysis, the current situation of technology transfer can be easily understood and based on this, the influence of technology transfer and the means to improve transfer efficiency can be easily to study in the future.

This report analyzed the technology transformation network and spatial distribution of Chinese universities, summarized the features and evolution patterns of the transformation between various regions and combined research results and the current situation in order to deduct the reasons behind the evolution and provide suggestions about how to promote cross region technology transformation to achieve collaborative innovation and economic development.

\section{Literature Review}

There are mainly three types of universities' technology transformation, including external-oriented transformation involving direct patent assignment and licensing, internal-oriented transformation involving university-based enterprises, and cooperative transformation involving the cooperation between universities and enterprises [1]. Since the traditional university technology transformation mode largely concentrated on CEEUSRO and the lack of patent data, most of the former studies in this field in China focused on macroscopic level or qualitative research, which can be concluded into four aspects as follows: (1) Researches on national technology transformation policy and innovation system; (2) Researches on scientific parks and enterprises based on or derived from universities; (3) Researches on the cooperation mode between universities and enterprises; (4) Researches on universities' innovation policy and transformation intermediary. And there are very few empirical studies based on patent data [2]. 
The lack of the empirical research limited scholars to explore further themes on that area.

In recent years, with the technology development and encouragement of national policy, patent transfer and technical contract have become positive interaction modes between universities and industries, which lead to a rapid increase of patent and trade data and therefore bring attention to researches. During that period, most of the scholars used social network theory based on patent licensing data or technical trade amount to construct transfer network and study the pattern, evolution and other features of the network. Tao Lei et al adopted visualized social network analysis method which analyzed the evolution process of university-enterprise cooperative application network from 1985 to 2008 from three aspects including region, technology and universities [3]. Yanyan Ma et al analyzed the scale, density and centrality of patent application network by establishing the Chinese university-enterprise cooperative patent application diagram [4]. Liguo Luo et al reached the conclusion that there is a positive correlation between the amount of patent licensing and the extent of knowledge exchange by studying knowledge exchange pattern of 985 universities based on patent data [5].

As the outcome of technology innovation, patent is crucial in realizing technology transfer [6]. Compared to patent licensing, patent assignment is more capable of ensuring uniformity of the ownership and right to use of a patent. The amount and development rate of patent assignment in Chinese universities largely exceed that of patent licensing, which demonstrates that patent assignment is better accepted in relevant industries. Besides, the direction of patent assignment can also illustrate the position of the main subject in technology transfer relations and networks more clearly than technical trade amount. To conclude, it is more reasonable to adopt patent assignment as the index to measure the technology transfer situation. Recently, several scholars attempt to analyze the transfer pattern based on patent assignment. Chunbo Zhang et al chose "985 project" universities as research samples and based their study on these universities' independently authorized patent data in SIPO (State Intellectual Property Office). They established patent assignment route by investigating information of assigner and assignee. By analyzing the relations between the universities which apply for the patent, assigner and assignee, the patent technology transfer of these universities can be concluded into 6 modes including direct transfer of patents, asset management, unit of university, university-enterprise cooperation in $\mathrm{R} \& \mathrm{D}$, local government-university cooperation in $\mathrm{R} \& \mathrm{D}$, academic entrepreneurship, patent-assertion entities [7]. Compared to the study on pattern and rough non-direction network, profounder research on technology transfer are benefit to illustrate lows and trends.

\section{Data and Research Method}

\subsection{Data Source}

This report chose the patent assignment data of our country's universities from 
2001 to 2016 to analyses the university technology transfer situation across different regions, and all the data came from the Incopat patent database. As one of the most authoritative patent database in China, Incopat patent database has been highly recognized by over 1000 institutional clients. The database collects more than 100 million pieces of patents and makes an integration of functions including analysis, monitoring and so on. Patent assignment includes the assignment of application right and the assignment of patent right. To reflect the real situation of universities' technology transfer, this report only used the patent assignment information of authorized patents before December 31, 2016 and the first applicant is university. According to the Figure 1 of patent assignment amount statistics, universities' patent assignment increased gradually from 2005 . And after a slow rise from 2005 to 2010, the growth rate experienced a significant increase after 2010, with the fastest growth rate appearing in 2013 and 2016. After pre-treatment and analysis of the data, this report chose the patent assignment data of four representative years to study the evolution trend, which are 2007, 2010, 2013 and 2016.

\subsection{Research Method}

In this report, two methods are mainly adopted including social network analysis and GIS spatial method.

Social network analysis method was used to establish the patent assignment network among universities of 31 provinces (HongKong, Macao, Taiwan excluded) across the whole country, in which the provinces are represented by the nodes. The ties between the nodes stand for patent assignments, and the directions of the ties stand for the directions of transfer. Social network analysis is widely used to analyses the knowledge flow and technology transfer which use patent as the medium [8]. For example, Thompson studied knowledge export across regions by patent quotation network [9]. Shangqi Si studied the cooperation network of different cities from patent alliance and found out that the key of promoting the development of the alliance is to cultivate cities with a strong po-

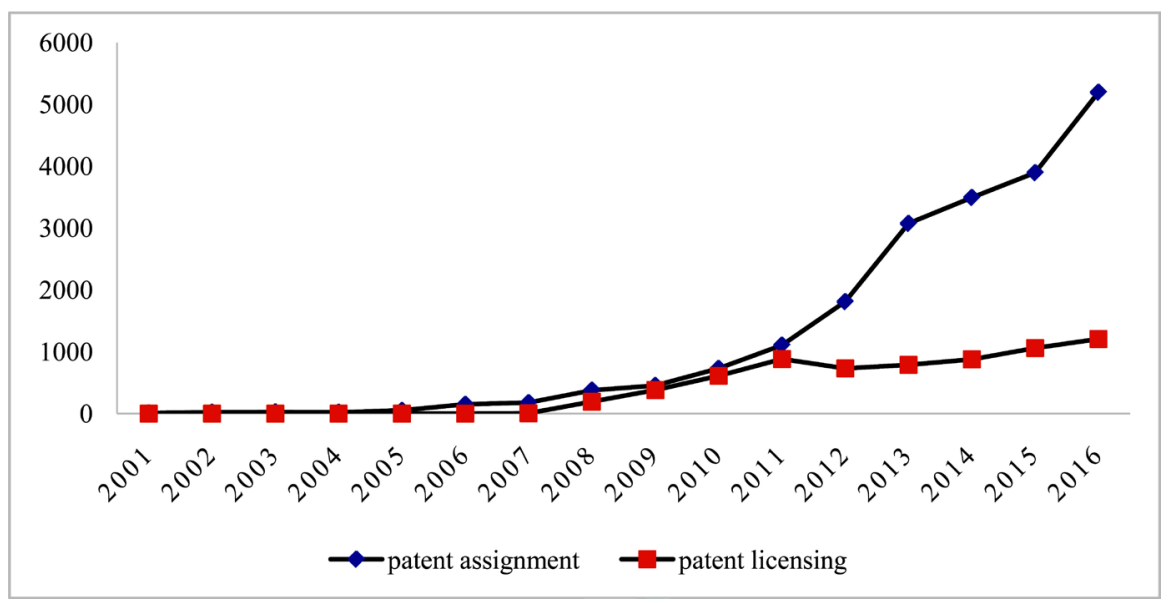

Source: data from incopat database.

Figure 1. The number of patent assignment and patent licensing, 2001-2016. 
tential to become medium [10]. Fengchao Liu et al used social network analysis method and adopted the concluded contract data of the underlying market to study the spatial distribution of cross region technology transfer network structure [11].

(1) Point centrality. The centrality of a node is the index to measure its power in the whole network, and it includes both absolute and relative centrality. In a directed network, absolute centrality can be divided into in-degree centrality (which stands for the number of nodes that are linked into this node) and out-degree centrality (which means the number of relations delivered from this node); relative centrality can be used to compare the point centrality of different networks, and it can be calculated by dividing a point's absolute centrality (which equals to the sum of in-degree and out-degree centrality) by the maximum possible point degree of the network [12].

(2) Reciprocity of relationship. There are three modes existing in a directed network, respectively no relationship, one-way relationship and both-way relationship. And in a both-way relationship, the two nodes are considered to have reciprocity. The proportion of reciprocity relationship in a network can reflect its stability, connectivity and equality between the nodes [13].

(3) Cliques of the network. Cliques are cohesive sub-groups founded on the reciprocity relationship, and they are maximal complete sub-graphs which at least contain three nodes. Any two nodes in a clique are directly related to each other, and no nodes which are related to all the nodes within the network can be found. In a directed network, cliques can only be analyzed when it is established among the nodes with reciprocity relationship. To better compare the network and spatial distribution, this report set 1 as the critical value to convert the multi-value network into bi-value network in clique analysis, and symmetrized the matrix according to the reciprocity principle.

Then the technology transfer activeness of the 31 provinces was measured on the basis of clique analysis. The regions were divided into blocks according to their activeness and then GIS spatial analysis method was adopted to combine the attributes of the blocks and geographic space in order to further analyze the spatial distribution and evolution patterns of cross region technology transfer.

\section{Empirical Analysis}

Integral analysis of universities' technology transfer network. Ucinet is employed to draw the network diagram (Figure 2) of universities' cross region technology transfer. From 2007 to 2016, the number of nodes and transfer, and the density of the network were gradually increasing. In 2007, the universities of 16 provinces in total in the network realized cross region technology transfer, with the universities of Jiangsu and Shanghai playing the leading role. In 2010, the number of provinces rose to 27, and Beijing, Shanghai, Jiangsu, Zhejiang all became central points of technology transfer. However, there were still many provinces which were isolated or only had single relationship. In 2013, the number reached 30 with Jiangsu and Beijing being the central nodes. In 2016, all the 31 provinces (Hongkong, Macao 


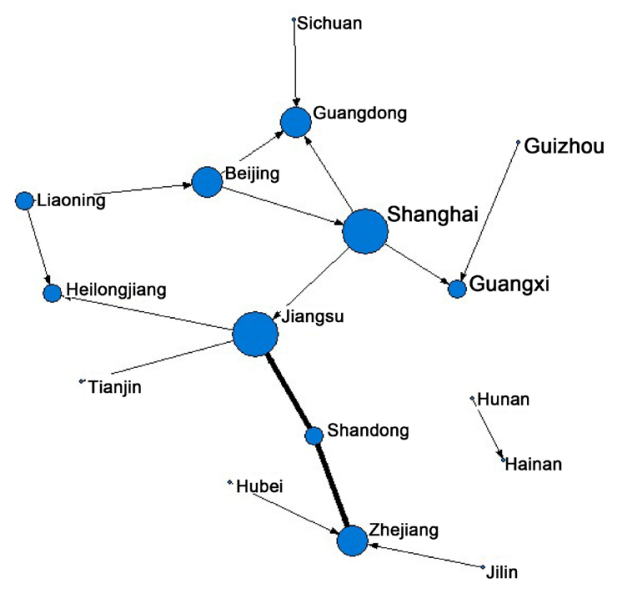

2007

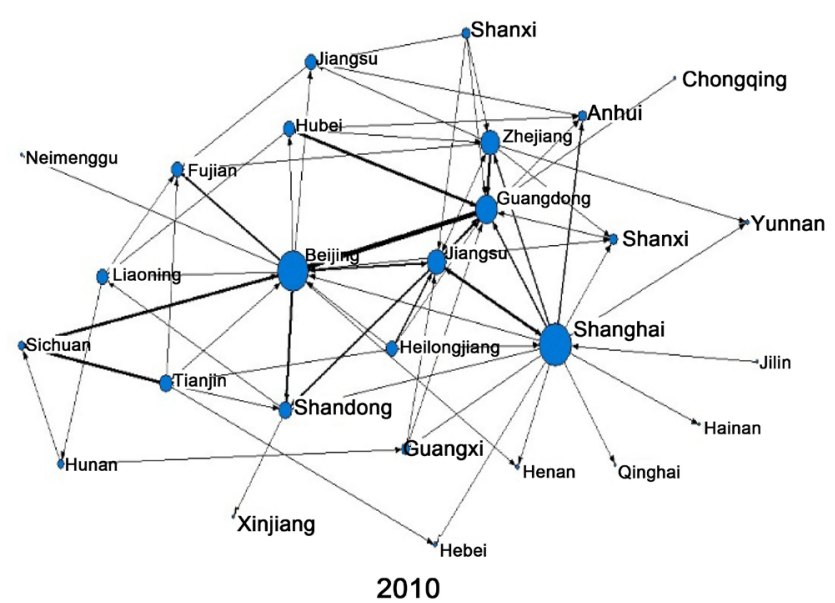

2010

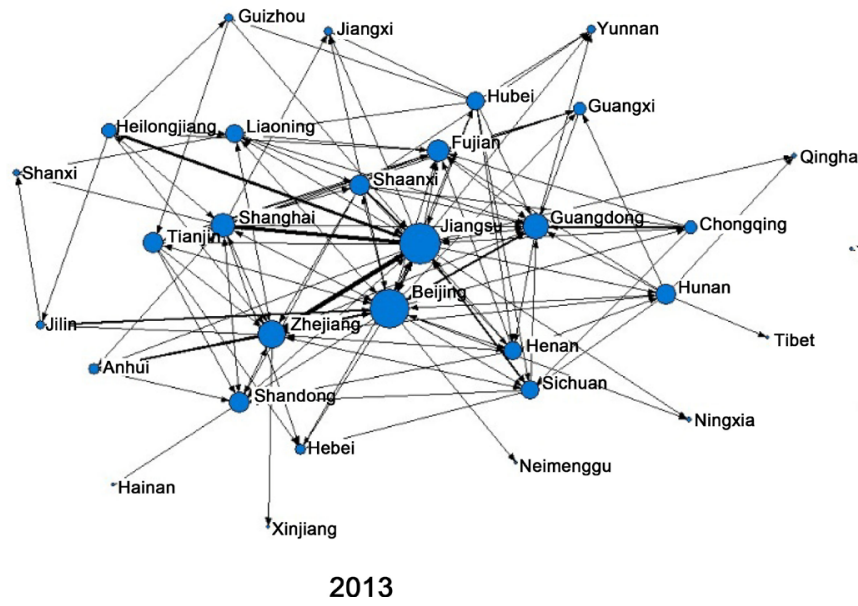

Source: own data base constructed from incopat data.

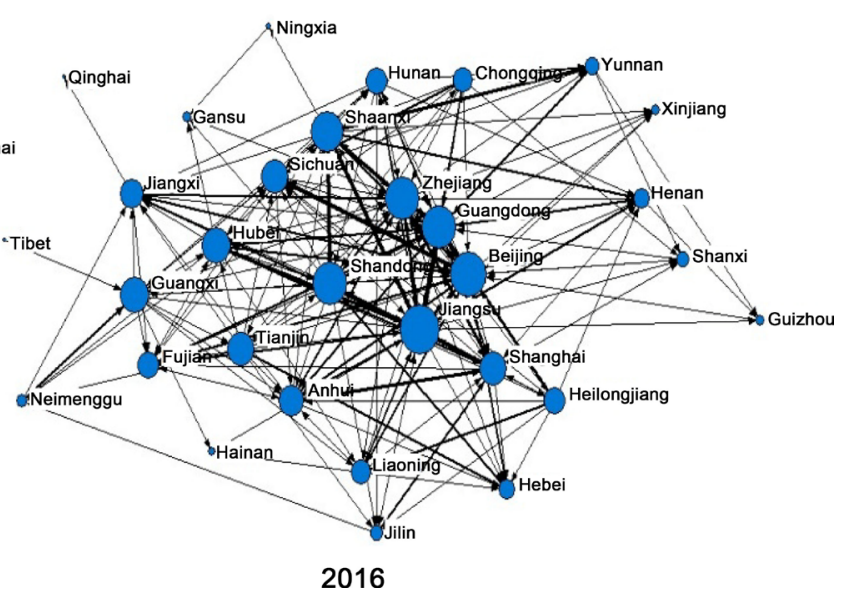

Figure 2. Universities' technology transfer network, 2007-2016.

and Taiwan excluded)were involved in the cross-region technology transfer with a drastic growth of central nodes. The developing trend of the transfer network demonstrates that the technology transfer level of our country's universities kept being improved and technology exchange between different regions became more and more frequent in the recent 10 years.

Attributes of the universities' technology transfer network nodes. By comparing the average value of network nodes centrality of different years, it was shown that from 2007 to 2016, the value increased from 1.13 to 30.68 , which indicated the rapid growth of technology transfer across provinces. According to the nodes' relative degree centrality (Figure 3), the cross-province technology transfer of Jiang$\mathrm{su}$ is the most frequent closely followed by Beijing, Guangdong, Shanghai and Zhejiang. The transfer level of Hubei, Shandong, and Heilongjiang has been significantly increasing in recent years and are grouped into the third echelon. Compared to these provinces, the technology transfer level of Gansu, Guizhou, Ningxia, Tibet, Qinghai, and Xinjiang was relatively low in the past 10 years. And technology export mainly took place in Beijing, Shanghai, Heilongjiang, Hubei, Jiangxi, Liaoning and Shaanxi, with Beijing and Shanghai being the 


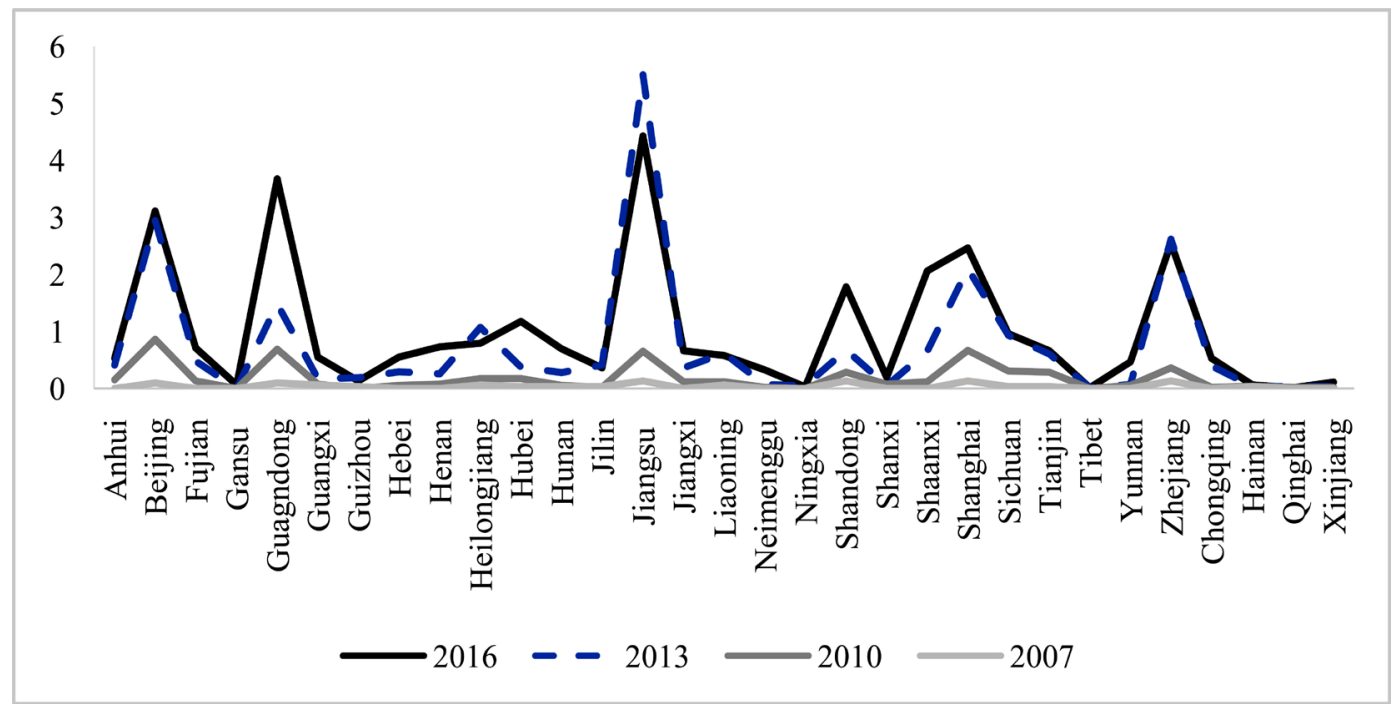

Source: own database constructed from incopat data.

Figure 3. Relatively point centrality of universities' technology transfer network, 2007-2016.

largest technology export sources. And in Fujian, Guangdong, Zhejiang and Shandong, the import of technology was significantly more frequent than export with Guangdong being the dominating transfer destination. When comparing the transfer data of 2010 and 2016 (Figure 4), it is shown that the technology transfer of Beijing, Shanghai and Guangzhou was still mainly one-way, although the difference between the amount of technology import and export was decreased; while the import and export of Jiangsu and Zhejiang provinces were quite balanced.

Overall, the total amount of universities' cross-region technology transfer keeps increasing, which indicates that universities lay emphasis on the technology transfer and they play a more and more important role in regional technology development and innovation. Beijing and Shanghai, where many universities are located, are still mainly technology export sources, while the provinces on the eastern coast, where economy is highly developed, are mainly receivers for technology transfer. The density of universities in a region influences the development of its science and technology to a certain extent, and the economic development level reflects its capability to receive technology transfer. The difference of transfer level between eastern and western area is still significant and the unbalance number between the technology import and export is still existing in many provinces.

Reciprocity of universities' technology transfer relationship. The gap of technology development level is a vital driving force of cross-region technology transfer. The transfer can be divided into three kinds, respectively bi-direction, one-way and no transfer. The mutual dyad transfer is considered as a "strong-strong" tie, and the relationship in a one-way transfer is considered as a "strong-weak" one. More reciprocity "strong-strong" relationship means that the cross-region technology transfer is more stable and the connectivity of the network is stronger. By analyzing the reciprocity, it is shown that there was no reci- 


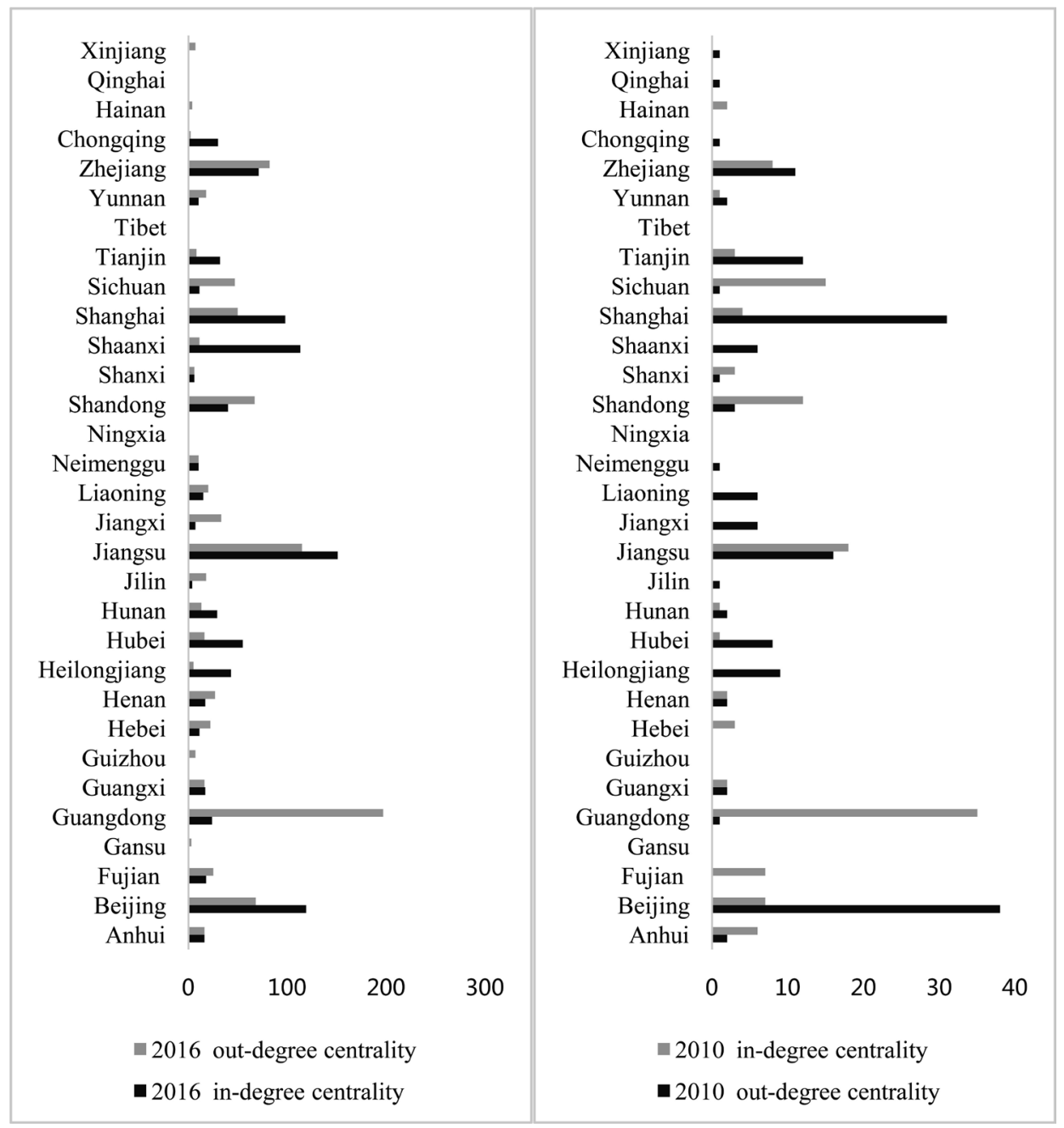

Source: own database constructed from incopat data.

Figure 4. In-degree centrality and out-degree centrality of network in 2010 and 2016.

procity relationship in the transfer network of 2007, which means there was no bi-direction technology transfer between different provinces and the stability of the network was very weak. From 2007 to 2016, the connectivity of technology between different regions was largely improved and the proportion of reciprocity relationship rose to $36.26 \%$, which also indicated that with the increase of the amount and efficiency of technology transfer, the gap of technology level between provinces was narrowed and the relationship equality was developed as well. These improvements led to a virtuous circle which can effectively promote the technology exchange between different regions.

The cliques of technology transfer network. The clique analysis is the analysis of cohesive sub-groups based on reciprocity. After the binarization and symmetrizing of universities' technology transfer network data of the past years, clique analysis was carried out and the minimum scale of the cliques was set as 5. It was demonstrated that in 2007, there was no clique with the scale of 5 or being larger than 5. In 2010, there was 1 qualified clique. In 2013, there were 24 cliques and 34 in 2016. The number of cliques from 2007 to 2010 shows that the universities' 
technology transfer of provinces around the country was not very active, and the reciprocity relationship was rare, which made it difficult to be analyzed. Therefore, the clique analysis of 2007 and 2010 were eliminated. The regions were divided into four categories by considering the number of cliques $(\mathrm{N})$ involved from 2013 to 2016, respectively core region $(\mathrm{N}>10)$, semi-core region $(6 \leq \mathrm{N} \leq$ $10)$, margin region $(1 \leq N \leq 5)$, and blank region $(N=0)$ (Table 1). The spatial distribution diagram of universities' cross-region technology transfer was drawn by GIS spatial distribution method (Figure 5 and Figure 6), and it showed that the transfer activeness kept decreasing when it came from southeast coast to northwest inland, with the core regions mainly locating in the southeast coast including Jiangsu, Zhejiang, Fujian, Guangzhou and also Beijing; the semi-core regions mainly located in the middle of the inland and around the Bohai Sea; the northwestern provinces were blank regions with very low transfer activeness. The overall transfer activeness in the spatial distribution map was significantly increased in 2016 compared with that of 2013. In term of spatial distribution, the distribution of core region was spreading from southeast coast are to inland, with Tianjin, Shandong, Anhui, Hubei, Shanxi, Sichuan and Guangxi becoming core regions as well. Most of these provinces are adjacent to original core regions, which indicate the positive impacts of core regions on the technology transfer level of provinces around. The provinces all have reciprocity relationship with at least 5 other provinces excluding Gansu, Guizhou, Ningxia, Xizang, Hainan and Qinghai.

\section{Discussion}

This report studied features and evolution process of universities' cross-region technology transfer from four aspects, including the overall network structure, the network nodes, the network relations and the spatial distribution of network blocks. Overall, the transfer level was largely increased from 2007 to 2016 with

Table 1. The number of cliques each province involved in 2013 and 2016.

\begin{tabular}{ccccccccc}
\hline Province & Y2013 & Y2016 & Province & Y2013 & Y2016 & Province & Y2013 & Y2016 \\
\hline Anhui & 1 & 12 & Hunan & 4 & 4 & Shanghai & 8 & 14 \\
Beijing & 24 & 30 & Jilin & 0 & 1 & Sichuan & 4 & 14 \\
Fujian & 8 & 6 & Jiangsu & 20 & 31 & Tianjin & 5 & 11 \\
Gansu & 0 & 0 & Jiangxi & 0 & 6 & Tibet & 0 & 0 \\
Guangdong & 15 & 29 & Liaoning & 3 & 5 & Yunnan & 0 & 2 \\
Guangxi & 3 & 13 & Neimenggu & 0 & 1 & Zhejiang & 10 & 24 \\
Guizhou & 0 & 0 & Ningxia & 0 & 0 & Chongqing & 3 & 3 \\
Hebei & 1 & 3 & Shandong & 5 & 22 & Hainan & 0 & 0 \\
Henan & 5 & 3 & Shanxi & 0 & 2 & Qinghai & 0 & 0 \\
Heilongiang & 0 & 8 & Shaanxi & 5 & 20 & Xinjiang & 0 & 1 \\
Hubei & 4 & 12 & & & & & & \\
\hline
\end{tabular}

Source: own database constructed from incopat data. 


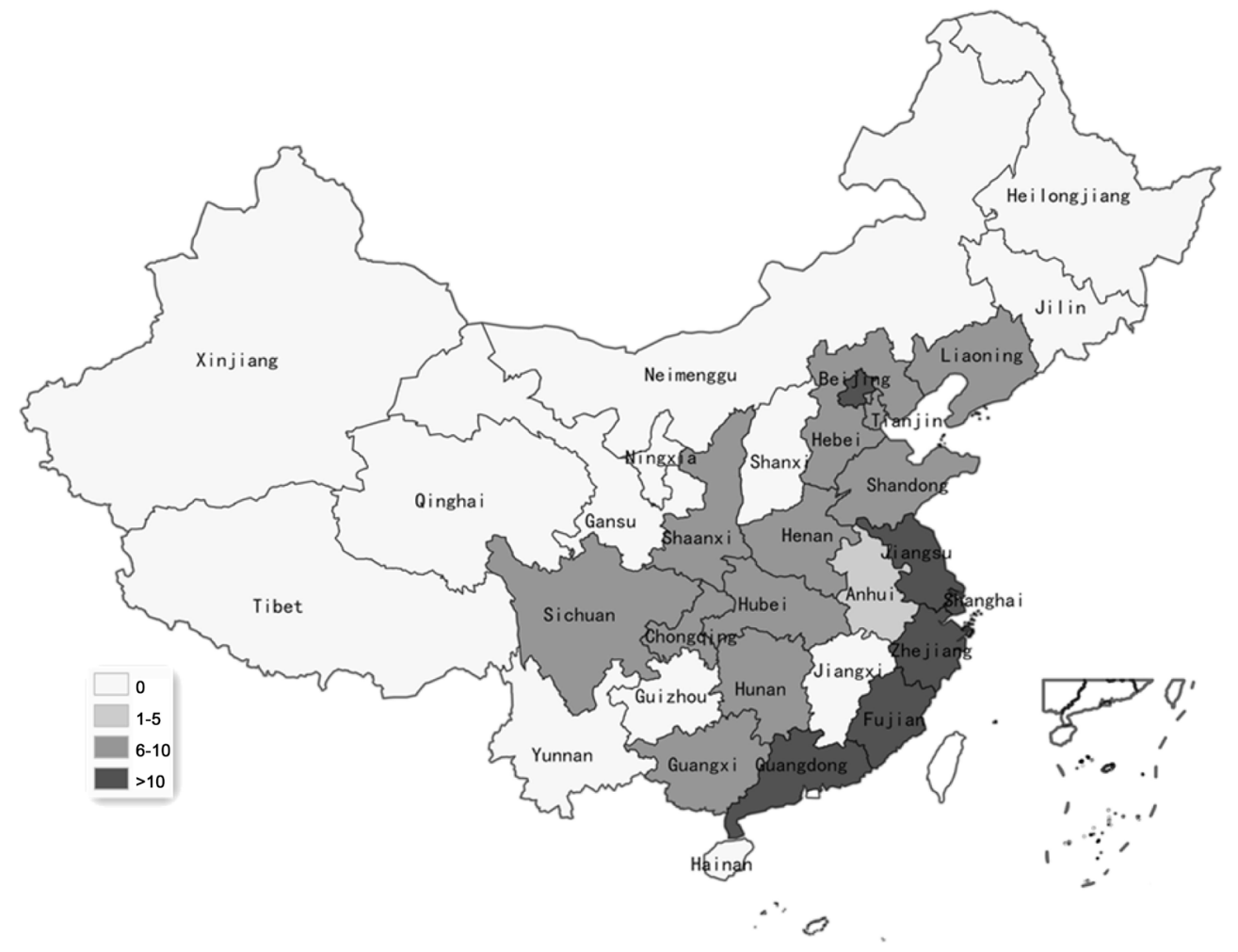

Source: own database constructed from incopat data.

Figure 5. The spatial distribution diagram of universities' cross-region technology transfer, 2013.

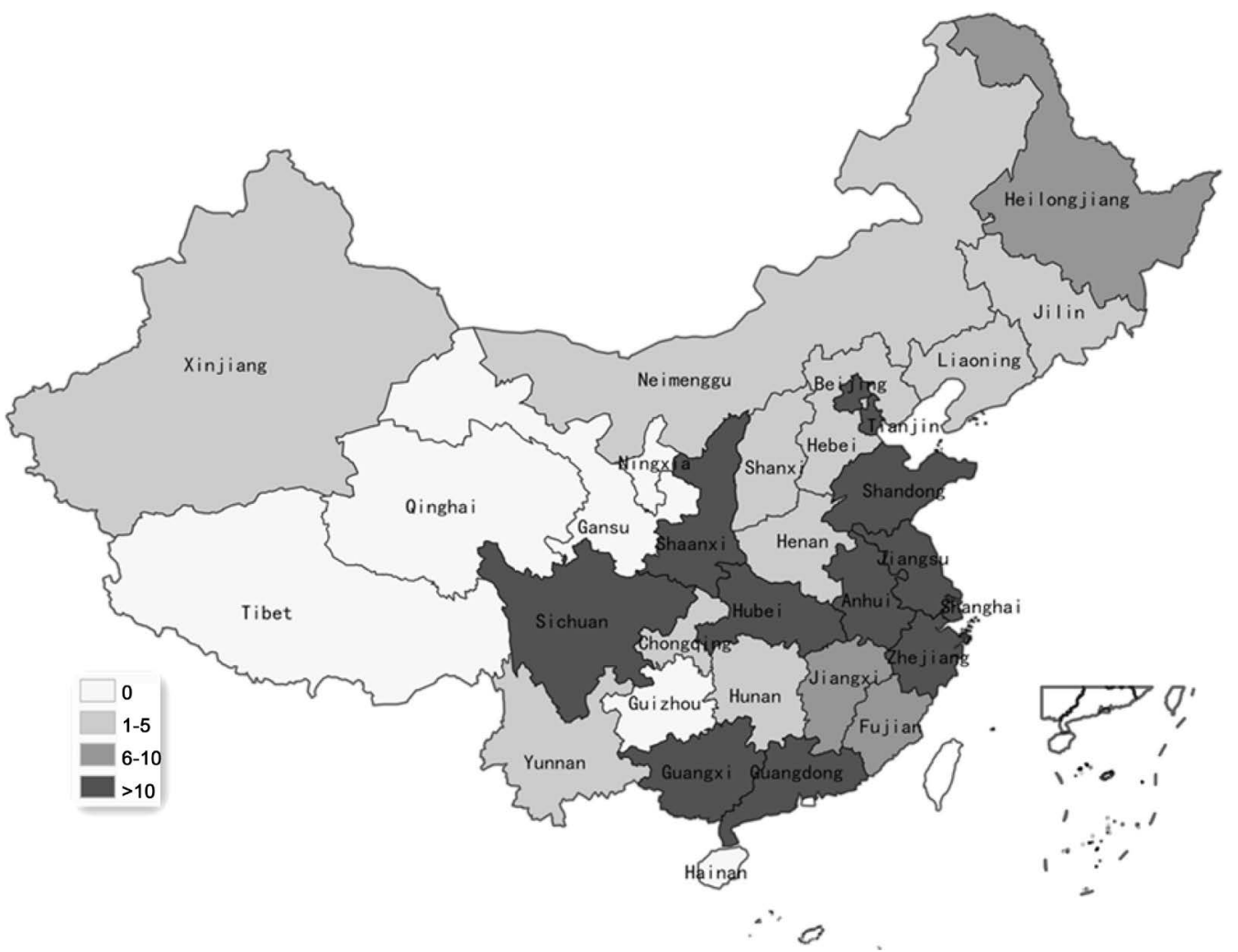

Source: own database constructed from incopat data.

Figure 6. The spatial distribution diagram of universities' cross-region technology transfer, 2016. 
the fastest growth rate taking place from 2013 to 2016 .

In term of technology import and export relationship, regions with rich education resources often have advantages in technology export, while main destinations for technology import located in economic developed area. There exists a common unbalance between the technology export and import level of the same province. The richness of education resource in a region decides the amount of technology that can be transferred, therefore it is a crucial thrust for technology transfer. On the other hand, increased economic development level creates the demand for technology. Currently, the main receivers of universities' technology transfer are enterprises, which are the main driving force of regional economic development, therefore economic development level is an important tension for technology transfer.

In the evolution of technology transfer network, the dyads of the transfer process generally turn from "strong-weak" into "strong-strong", which increases the reciprocity level of the network. There exists a positive correlation between the connectivity of the network nodes and the transfer activeness of universities' technology. As to the spatial distribution of the technology transfer, there is a trend that core regions spread from southeast coast to inland, and the provinces belonging to core regions have significant positive effects on the technology level of the provinces around. Besides, the improvement of technology transfer level of less developed inland provinces such as Qinghai, Xizang and Gansu is very slow. The cross-region technology transfer shows a typical geographic feature. On one hand, different geographic locations lead to the difference of the regions' economic development level and resources, which further influences the transfer level of the region. On the other hand, the geographic distance between the two sides of the technology transfer can limit the transfer level, therefore the technology exchange tends to take place between adjacent provinces.

\section{Contribution and Study Implications}

The paper analyzes the universities' technology transfer network and evolution of spatial distribution based on the patent assignment data. Most of the former research on the cross-regional technology transfer only focused on analyzing the feature of the network and spatial distribution at a particular year or regional. However, besides that the paper also concentrates on the evolution of the network and spatial distribution. Through the evolution process, the trends and laws of technology transfer can be found. The results show the key actor and relations in the transfer network and the trend of the evolution. From the practical social aspects, it's helpful to universities and regional governments thinking useful way to improve the transfer efficiency and effectiveness, for national government, the research is not only illustrating the regional transfer situations but also give the suggestions on narrowing the technology gaps between difference regions. From the academic aspects, the paper contributes to the literature by establishing the basic research on cross-regional technology transfer, based on our paper, the further research including the study on the influence factor and 
the impact of technology transfer to regional innovation capability could be easily carried out.

\section{Conclusions}

After analyzing the evolution pattern of universities' technology transfer network and its spatial distribution and considering the current situation in our country, it is recommended that:

1) In term of provinces, the main driving force of technology transfer is the universities' technology innovation sources and the regional economic development level is the important pulling force. Therefore, to ensure the technology transfer can be further promoted, it is vital to improve innovation level of universities and break the barrier between the universities and the enterprises. And to develop characteristic industries of the regions and to improve regional economy combining the advantages of the region are basic approaches to attract technology import.

2) In term of the whole country, it is essential to eliminate the distance limitation of cross-region technology transfer and to solve the information dissymmetry in the transfer process to make sure the transfer can be successfully carried out. There are all kinds of barriers existing in the technology transfer between universities and industries, or between different regions, and other factors such as geographic distance further aggravate the information dissymmetry. Therefore, it is effective to improve the technology transfer efficiency by establishing platforms for cross-region technology transfer and interaction between universities and enterprises, which can eliminate the barriers created due to geographic distance or policies.

Finally, the study also has some limitations. Except patent assignment, technology transfer also including other methods like patent licensing, technology exchange and so on. Even the patent assignment is the main part of technology transfer in China now, research on other parts also need studied. Based on the evolution of transfer network and spatial distribution, this paper gives the possible reasons which influence the cross-regional technology transfer and the suggestion on improving the transfer efficiency, however, we need do more correlation analysis to explore degree of influence in the future.

\section{References}

[1] Wu, Z.L. and Ding, X. (2005) The Study on Universities' Technology Transfer Methods. Science and Technology Management Research, 25, 116-118.

[2] Chen, A., Patton, D. and Kenney, M. (2016) University Technology Transfer in China: A Literature Review and Taxonomy. The Journal of Technology Transfer, 41, 891-929. https://doi.org/10.1007/s10961-016-9487-2

[3] Lei, T. and Chen, X.D. (2011) Network Map Analysis of University-Firm's Co-Application for Patents. Science Research Management, 32, 67-73.

[4] Luo, L.G., Yu, X. and Zhou, L.H. (2013) Knowledge Flow Capability of "985 Universities" Based on Patent License Network. Chinese Journal of Management, 10 , 458-462.

[5] Ma, Y.Y., Liu, C.F. and Sun, Y.T. (2011) Research on Chinese University-Enterprise 
Cooperation Network of Patent Applications. Studies in Science of Science, 29, 390395.

[6] Meyer, M. (2002) Tracing Knowledge Flows in Innovation Systems. Scientometrics, 54, 193-212. https://doi.org/10.1023/A:1016057727209

[7] Zhang, C.B., Yang, Y., Ding, K. and Liu, Z.Y. (2016) Analysis and Prospect of Patent Technology Transferring Modes of Chinese Universities: Evidences from 985 Project Universities. Science and Technology Process and Policy, 33, 117-121.

[8] Sternitzke, C., Bartkowski, A. and Schramm, R. (2008) Visualizing Patent Statistics by Means of Social Network Analysis Tools. World Patent Information, 30, 115131.

[9] Thompson, P. and Fox-Kean, M. (2005) Patent Citations and the Geography of Knowledge Spillovers: A Reassessment. American Economic Review, 95, 450-460. https://doi.org/10.1257/0002828053828509

[10] Si, S.Q. and Feng, F. (2010) Research on Chinese Inter-Regional Technology Transfer Alliance-Based on Cooperative Network of 38 Cities. Studies in Science of Science, 28, 1165-1170.

[11] Liu, F.C. andMa, R.K. (2013) Study on the Network Structure and Spatial Distribution of Inter-Regional Technology Transfer: Analysis Based on Inter-Provincial Technical Market Transaction of China in 2006-2010. Studies in Science of Science, No. 4, 529-536.

[12] Liu, J. (2009) Lectures on Whole Network Approach: A Practical Guide to. Gezhi Press, Shanghai.

[13] Hanneman, R.A. and Riddle, M. (2005) Introduction to Social Network Methods.

Submit or recommend next manuscript to SCIRP and we will provide best service for you:

Accepting pre-submission inquiries through Email, Facebook, LinkedIn, Twitter, etc. A wide selection of journals (inclusive of 9 subjects, more than 200 journals)

Providing 24-hour high-quality service

User-friendly online submission system

Fair and swift peer-review system

Efficient typesetting and proofreading procedure

Display of the result of downloads and visits, as well as the number of cited articles

Maximum dissemination of your research work

Submit your manuscript at: http://papersubmission.scirp.org/

Or contact jssm@scirp.org 